\title{
Separation of carvone by batch distillation from the mixture obtained from limonene oxidation
}

\author{
Separación de carvona mediante destilación discontinua de la mezcla obtenida de oxidación \\ de limoneno \\ Jaime Andrés Becerra (iD ${ }^{1}$ Aída Luz Villa \\ ${ }^{1}$ Departamento de Ingeniería Química, Universidad de Antioquia. Calle 70 \# 52-21. A. A. 1226. Medellín, Colombia.
}

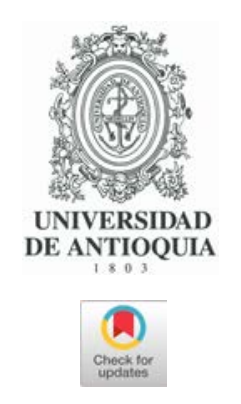

\section{CITE THIS ARTICLE AS:}

\author{
J. A. Becerra and A. L. Villa. \\ "Separation of carvone by \\ batch distillation from the \\ mixture obtained from \\ limonene oxidation", Revista \\ Facultad de Ingeniería \\ Universidad de Antioquia, \\ no.104, pp. 118-128, Jul-Sep \\ 2022. [Online]. Available: \\ https: \\ //www.doi.org/10.17533/ \\ udea.redin. 20210848
}

\section{ARTICLE INFO:}

Received: May 19, 2020 Accepted: August 24, 2021

Available online: August 24, 2021

\section{KEYWORDS:}

Essential oil; limonene; separation; simulation

Aceite esencial; limoneno; separación; simulación
ABSTRACT: Limonene is the main constituent of citrus oils whose oxidation produces a set of fine chemical compounds such as carvone, carveol, and limonene 1,2-epoxide. This contribution reports the results of the experimental evaluation and computational simulation of carvone separation by fractional distillation from the reaction mixture. Carvone was obtained from limonene oxidation over a perchlorinated iron phthalocyanine supported on modified silica catalyst $\left(\mathrm{FePcCl}_{16}-\mathrm{NH}_{2}-\mathrm{SiO}_{2}\right)$ and t-butyl hydroperoxide (TBHP) as oxidant. Both experimental and simulation results support that fractional distillation (in batch and continuous) is a suitable technique for concentrating carvone. However, in the presence of water, the formation of immiscible $L-L$ phases makes the experimental separation of carvone more difficult. Simulation results of the batch distillation incorporating the NRTL-RK thermodynamic model indicate that if water, acetone, and $t$-butanol are previously removed from the reaction mixture, carvone composition can be enriched in the reboiler from $4 \%$ up to $50 \%$, or around $86.5 \%$ if the removal is in a third distillate cut under vacuum conditions.

RESUMEN: El limoneno es el principal componente de los aceites cítricos de cuya oxidación se obtienen compuestos de química fina tales como carvona, carveol y epóxido de 1,2-limoneno. En esta contribución se reportan los resultados de la evaluación experimental y mediante simulación computacional del proceso de separación de carvona mediante destilación fraccionada por lotes de la mezcla de reacción. La carvona se obtuvo a partir de la oxidación de limoneno con una ftalocianona clorada de hierro soportada en sílice modificada como catalizador heterogéneo $\left(\mathrm{FePcCl}_{16}-\mathrm{NH}_{2}-\right.$ $\mathrm{SiO}_{2}$ ) y el agente oxidante hidroperóxido de terc-butilo. A partir de los resultados experimentales y las simulaciones se infiere que la destilación fraccionada (por lotes y en continuol es una técnica adecuada para la concentración de carvona. Sin embargo, en presencia de agua, la formación de fases L-L inmiscibles hace que la separación experimental de carvona sea más difícil. Los resultados de simulación empleando el modelo termodinámico NRTL-RK indican que si se retira previamente de la mezcla de reacción la mayor cantidad posible de agua, acetona y terc-butanol, la mezcla líquida con una fracción molar de $4 \%$ de carvona, se puede enriquecer en el rehervidor hasta un $50 \%$, o cerca de $86,5 \%$ si se retira en una tercera fracción de destilado operando en vacío.

\section{Introduction}

The cyclic monoterpene $d$-limonene is the main constituent of citrus essential oils extracted from the

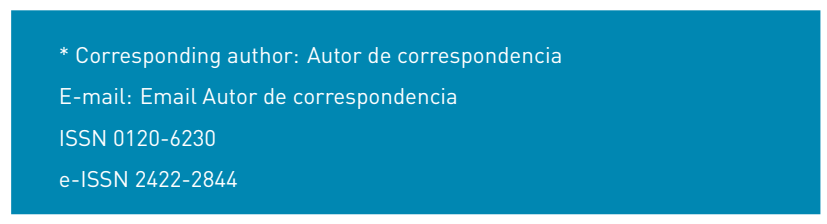

peels of oranges, tangerines, lemons, and grapefruits, whereas the levo isomer l-limonene is usually found in pine oils in low concentrations [1-3]. Carvone is a cyclic ketone obtained from limonene oxidation with a high commercial cost $\left(>10 U S D \mathrm{~kg}^{-1}\right)$ and is used in the synthesis of specialty chemical products for the food, pharmaceutical, agrochemical, and perfume industries [4-6]. However, from the oxidation of limonene with $t$-butyl hydroperoxide (TBHP) as the oxidizing agent and perchlorinated iron 
phthalocyanine on modified silica catalyst $\left(\mathrm{FePcCl} l_{16}-\right.$ $\mathrm{NH}_{2}-\mathrm{SiO}_{2}$ ), Figure 1, other by-products such as limonene 1,2-epoxide and carveol are obtained lacetone, $313 \mathrm{~K}, 6 \mathrm{~h}, 750 \mathrm{rpm}$, TBHP/limonene $=2.6 \mathrm{~mol} / \mathrm{mol}, 84$ mg catalyst), with a limonene conversion of $76 \%$ and TBHP of $97 \%$; additionally, t-butanol is obtained from the decomposition of TBHP [7].

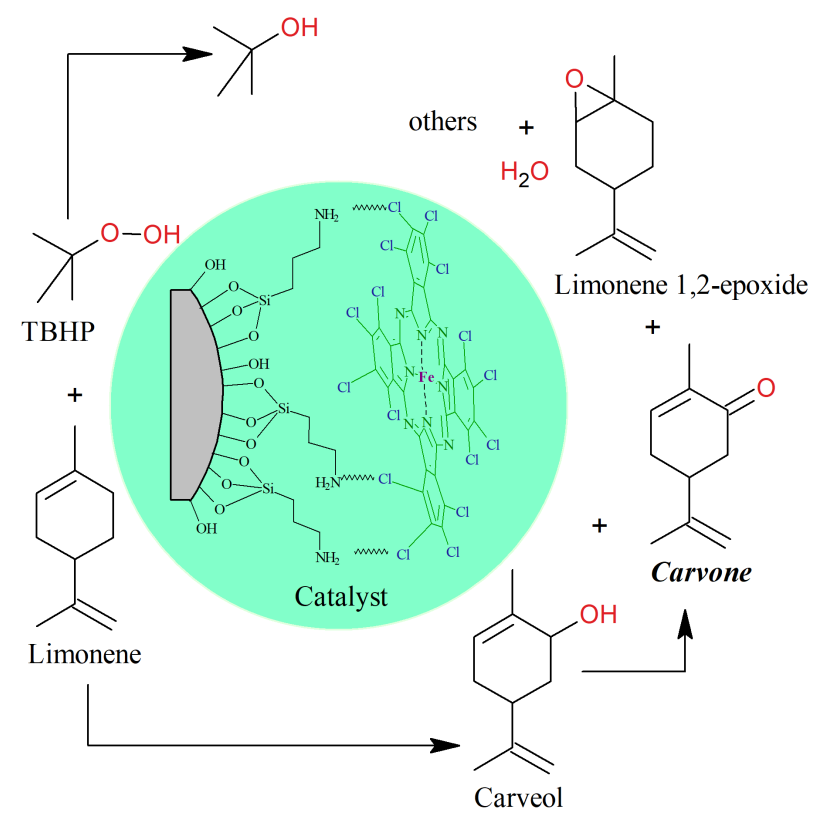

Figure 1 Catalytic oxidation of limonene over $\mathrm{FePCCl}_{16}-\mathrm{NH}_{2}-\mathrm{SiO}_{2} / \mathrm{TBHP}$

Distillation is a physical separation process by selective evaporation and condensation of the components in a mixture regularly carried out continuously, in batch or semi-continuously, which results in a total or partial separation increasing the concentration of some components in the mixture due to the differences in volatility [8]. The continuous distillation is thermodynamically and economically efficient to purify large quantities of material of constant composition $[8,9]$. In contrast, the batch distillation is more versatile [10] and is often used to produce small quantities of products with high purity of variable compositions, commonly in biochemical, biomedical, pharmaceutical and fine chemical industries [9]. In the usual operation of a conventional multi-stage batch distillation system, Figure 2 , the distillate is continuously removed from the system until the distillation ends. If a very high purity of a product (distillate or bottoms) is needed, a multi-stage column is added to the discontinuous distillation system. In general, the relationship for multi-stage distillation can be obtained by performing step-by-step calculations $[8,9]$. This technique has been extensively used in experimental and simulation studies to fractionate mixtures containing essential oils and monoterpenes such as the combination of supercritical $\mathrm{CO}_{2}$ and vacuum distillation for the fractionation of bergamot oil 10.35-0.4 kPa, 298-338 $\mathrm{K}$, recovery oxygenated compounds > 85\%] [11]. The separation of essential oil constituents by batch vacuum distillation to the recovery of a $98.89 \%$ eucalyptol fraction from $E$. globulus and a $98.53 \%$ citronellal fraction from $E$. citriodora (18 trays, column holdup of $5 \%, 10 \mathrm{kPa}$, reflux ratio $=8$ ) [12]. The fractionation of citronella (Cymbopogon winterianus) essential oil and concentrated orange oil phase by batch vacuum distillation (0.1 - $2 \mathrm{kPa}$ ) has also been reported with a high efficiency affording complete separation of limonene, with a rich citronellal fraction and stream constituted mainly by citronellol and geraniol [13]. The simulation of limonene epoxide distillation from a mixture containing limonene, acetonitrile, water and limonene epoxide has also been reported [14].

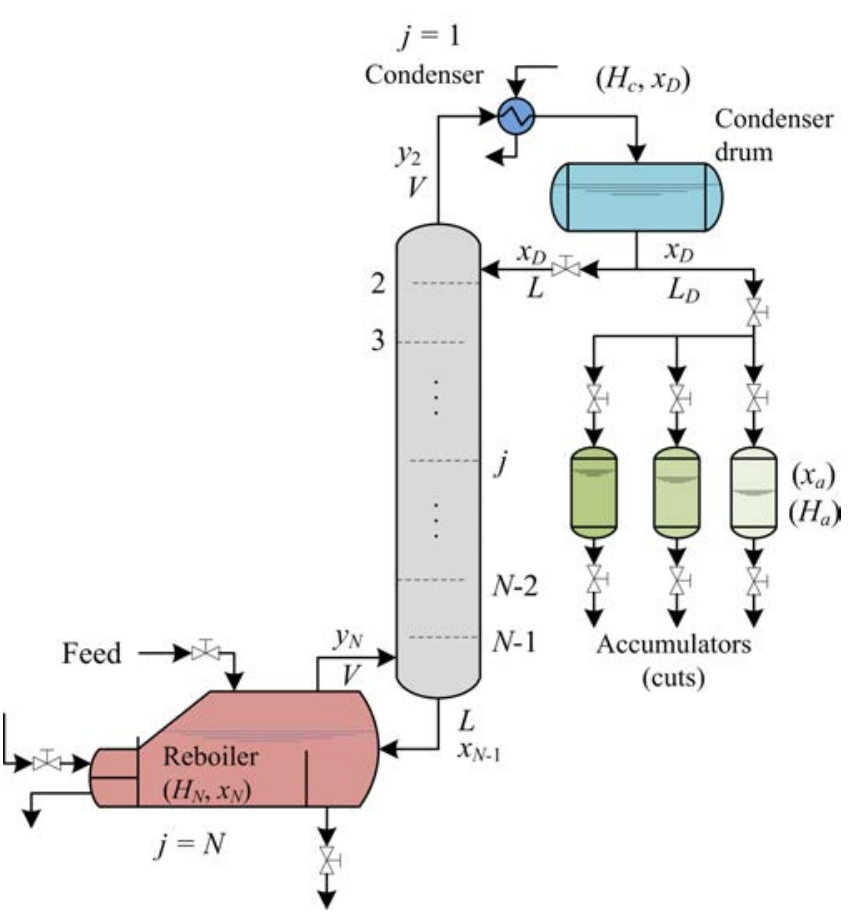

Figure 2 Diagram of the conventional multi-stage batch distillation equipment

Regardless of the operation mode, modeling approaches for distillation equipment can use approximate and rigorous mathematical models [15]. Approximate or simple models usually assume that the dynamic behavior of the column can be approximated as a sequence of steady states (pseudo-stationary state approximation), which is true when both the holdup of liquid in the column stages and the reflux tank can be neglected compared to the holdup of liquid in the reboiler. The main advantage of these models is their calculation speed, although they may have lower precision than rigorous models in some cases, and most of them are limited to mixtures of constant relative volatility. They are used in preliminary studies of 
process design and optimization, when it is necessary to evaluate a large number of cases, as in this study. Rigorous models are used when a more realistic representation of column dynamics is required; however, they usually require more calculation speed. This paper presents the evaluation of the experimental separation process of carvone by batch distillation of the reaction mixture obtained from the limonene oxidation and the simulation of the separation process to determine the operating conditions that increase the recovery of carvone using an approximate model.

\section{Experimental section}

\subsection{Catalyst synthesis and chemical reactions}

(1R)-(+)-Limonene (97\%) and aqueous TBHP solution (70\%) from Sigma-Aldrich and acetone (99.5\%) from Merck, were used without further purification. The $\mathrm{FePcCl} \mathrm{Pl}_{16}-\mathrm{NH}_{2}-$ $\mathrm{SiO}_{2}$ catalyst was synthesized according to the procedure reported in the literature [7]. The oxidation of limonene with TBHP was carried out in a batch reactor of $8 \mathrm{~mL}, 318$ $\mathrm{K}, 750 \mathrm{rpm}, 6 \mathrm{~h}, \mathrm{TBHP} /$ limonene molar ratio of 2.6 , with acetone as a solvent and $120 \mathrm{mg}$ of $\mathrm{FePcCl}_{16}-\mathrm{NH}_{2}-$ $\mathrm{SiO}_{2}(55.5 \mu \mathrm{mol} \mathrm{Fe} / \mathrm{g})$. The catalyst was filtered out from the reaction mixture and the filtrate was analyzed in a gas chromatograph (GC) Agilent 7890A equipped with FID, TCD and mass spectrometer (MS) Agilent 5975C detectors, with a HP5 column $(0.20 \mathrm{~mm} \times 50 \mathrm{~m} \times 0.5 \mu \mathrm{m})$. Several batches were carried out and mixed for the distillation experiments.

\subsection{Batch distillation tests}

The filtered reaction mixture was fractionated at atmospheric and vacuum pressure in an 800-Micro-Fractional-Distillation system from B/R-Instruments Corp., under batch conditions and using a cyclic total reflux (CTR) operation policy; i.e., alternating the internal reflux ratio $r$ between 0 and 1 . The distillation equipment uses a spinning band column that rotates at high revolutions, forcing the contact between the vapors with the condensed liquid that falls on the column wall. This contact takes place in a thin layer renewed thousands of times per minute, providing a very efficient separation. The quantification of the distillation fractions was also carried out with a GC-MS.

\subsection{Modeling and simulation}

The purification of carvone after removing the most volatile compounds from the reaction mixture was evaluated with an approximate mathematical model for the distillation process and executed using Matlab ${ }^{\circledR}$ software. The model assumes constant relative volatilities and constant internal reflux ratio. The ode15s function was used to solve numerically the ordinary differential equations of the mathematical model; the relative volatilities estimated through simulation in Aspen Plus ${ }^{\circledR}$ V.8 software with the NRTL-RK thermodynamic method.

\section{Approximate model of the batch distillation for carvone purification}

The approximate mathematical model for the batch distillation equipment in Figure 2 was based on the assumptions of constant molar holdups in the condenser $\left(H_{c}\right)$ and the internal stages $\left(H_{j}\right)$, total condensation without subcooling, negligible vapor holdup, perfect mixing between liquid and vapor in the stages, insignificant heat losses, theoretical stages, feed mixture at its bubble point, adiabatic column, negligible pressure drop across the column and constant relative volatilities [8,9]. The set of equations used to model the column with a separation capacity of $N$ ideal trays is given by Equations 1 to 14 . The accumulation of liquid in the pot or reboiler holdup is described by Equation 1, and the liquid molar composition of components $i$ by Equation 2

$$
\begin{gathered}
\frac{d H_{N}}{d t}=L-V \\
\frac{d x_{N, i}}{d t}=\frac{L}{H_{N}}\left(x_{N-1, i}-x_{N, i}\right)-\frac{V}{H_{N}}\left(y_{N, i}-x_{N, i}\right)
\end{gathered}
$$

The liquid molar composition in the internal stages is given by Equation 3. The holdup of liquid in the condenser tank by Equation 4 and the liquid molar fraction in the condenser or distillate by Equation 5:

$$
\begin{gathered}
\frac{d x_{j, i}}{d t}=\frac{L}{H_{j}}\left(x_{j-1, i}-x_{j, i}\right)-\frac{V}{H_{j}}\left(y_{j, i}-y_{j+1, i}\right) \\
\frac{d H_{c}}{d t}=V-L-L_{D}=0 \\
\frac{d x_{D, i}}{d t}=\frac{V}{H_{c}}\left(y_{2, i}-x_{D, i}\right)
\end{gathered}
$$

The distillate accumulator molar holdup and compositions are defined by Equation 6 and 7, respectively:

$$
\begin{gathered}
\frac{d H_{a}}{d t}=L_{D} \\
\frac{d x_{a, i}}{d t}=\frac{L_{D}}{H_{a}}\left(x_{D, i}-x_{a, i}\right)
\end{gathered}
$$

The estimation of the vapor molar fraction at each stage using thermodynamic equilibrium relationships is given by Equation 8, distribution coefficients by Equation 9, and inequality constraints for the compositions of liquid and vapor by Equations 10,11. The molar flow of liquid in the 
column is described by Equation 12, in the distillate by Equation 13, and the relationship between internal and external reflux ratio by Equation 14:

$$
\begin{gathered}
y_{j, i}=K_{j, i} x_{j, i} \\
K_{j, i}=\frac{\alpha_{i}}{\sum \alpha_{i} x_{j, i}} \\
x_{j, n_{c}}=1-\sum_{i=1}^{n_{c}-1} x_{j, i} \\
y_{j, n_{c}}=1-\sum_{i=1}^{n_{c}-1} y_{j, i} \\
L=r V \\
L_{D}=(1-r) V \\
R=r /(1-r)
\end{gathered}
$$

\section{Results and discussion}

\subsection{Experimental evaluation of carvone separation}

After the reaction, the catalyst was removed and the GC-MS analysis of the resulting liquid sample showed as main components the solvent acetone, $t$-butanol from TBHP decomposition, the remaining unreacted reagents (limonene and TBHP), and the main monoterpene-derived reaction products (carvone, carveol and limonene 1,2-epoxide), among others terpenes [7], Table 1. Additionally, the large amount of water entering with the oxidizing agent remains almost constant during the reaction, since just small amounts can be obtained from the limonene transformation and secondary TBHP reactions [7]. The liquid reaction sample was fractionated by batch distillation and the separation was conducted under a cyclic total reflux policy with intermittent internal reflux ratio, i.e., varying $r$ intermittently between 0 and 1. At $90.7 \mathrm{kPa}$ and $4.5 \mathrm{~h}$ of operation, the most volatile components of the reaction mixture lacetone, t-butanol and limonene) were withdrawn. Then, under vacuum conditions $(0.27 \mathrm{kPa}, 1 \mathrm{~h})$ and after having removed the aqueous phase from the reaction mixture, carvone concentration increased (see Figure 3).

The reaction mixture was initially placed into the reboiler at $298 \mathrm{~K}$ and $90.7 \mathrm{kPa}$. The heat was added at total internal reflux ratio $(r=1)$, reaching the first steady-state equilibrium zone SS1 with a boiling point of $339 \mathrm{~K}$. The first distillate cut $F_{1}$ (Dist) was collected between 339 and
$352 \mathrm{~K}$ at $r=0$, its free-water composition was mainly $82.5 \%$ acetone, $16 \% t$-butanol and $1.5 \%$ limonene. The secondary distillate cut $F_{2}$ (Dist) was analyzed considering the fractions between $356-357 \mathrm{~K}$ and 360-363 $\mathrm{K}$ after reaching the steady-state equilibrium zones $S S_{2}$ and $S S_{2}$, respectively. The main free-water components of this second cut were $t$-butanol, limonene, acetone, and TBHP, Table 1. Although the fractions $F_{1}$ (Dist) and $F_{2}$ (Dist) were visually in one phase and the boiling point of the mixture is below the normal boiling point of pure water, this does not guarantee the absence of water in the cuts. Ternary $L-L$ equilibria simulation of aqueous systems containing acetone, $t$-butanol and TBHP (see Figure 4), suggests that the distillate cuts should probably be water-free or having small amounts of it, as the obtained fractions are in a single liquid phase.

On the other hand, the distillation at atmospheric conditions after collecting the second fraction resulted in the formation of an immiscible $L-L$ mixture in the reboiler because of the presence of a large amount of water and terpenes, as was predicted by the ternary $L-L$ aqueous mixtures, Figure 4. Reports of the liquid-liquid equilibrium experimental data of the ternary system containing water + acetone + limonene at $298.15 \mathrm{~K}$, and its simulated correlation by the modified UNIQUAC model [16], are in agreement with our simulation results. Thus, it is expected that this mixture has the largest amount of water to be removed from the reboiler. Additionally, it is not desirable to separate water as the previous cuts to avoid bottom products damage, due to the sudden temperature increasing up to $433 \mathrm{~K}$ when the last drop of the aqueous phase is evaporated (results are not presented here). Thereby, after $4.52 \mathrm{~h}$ of operation, the distillation was stopped, the $\mathrm{L}-\mathrm{L}$ reboiler mixture was separated by centrifugation in a third aqueous and organic bottom fractions.

The third aqueous bottom fraction $F_{3}, A Q$ (bott) mainly contained TBHP, acetone and $t$-butanol, among others. On the other hand, the organic bottom fraction $F_{3}, O R G$ (bott) was mainly constituted by limonene, $13 \%$ carvone, acetone, and $t$-butanol, among others, Table 1 . The fractionation of the $F_{3}, O R G$ (bott) under vacuum conditions $(300 \mathrm{~K}$ and $0.27 \mathrm{kPa}$ ) gave the last bottom fraction $F_{4}$ (bott) after 357 K. However, it was not highly enriched due to the remaining material in the bottom was not enough to complete the recirculation in the distillation column. The free-water composition of the $F_{4}$ (bott) sample after $0.75 \mathrm{~h}$ was mainly $14 \%$ carvone, $11 \%$ acetone, $9 \% t$-butanol, $4 \%$ limonene, $1 \%$ limonene 1,2-epoxide, $1 \%$ carveol, among others, Table 1. 
Table 1 Experimental composition of the reaction mixture and the liquid fractions during the fractional batch distillation

\begin{tabular}{|c|c|c|c|c|c|c|c|c|c|}
\hline & \multicolumn{3}{|c|}{ Reaction } & \multicolumn{3}{|c|}{ Atmospheric distillation $^{1}$} & \multirow[b]{2}{*}{$\begin{array}{l}F_{3}, \text { ORG } \\
\text { (Bottom) }\end{array}$} & \multicolumn{2}{|c|}{ Vacuum distillation $^{1}$} \\
\hline $\begin{array}{l}\text { Compo- } \\
\text { sition }^{2}\end{array}$ & $\begin{array}{c}\mathrm{RT} \\
\text { (min) }\end{array}$ & End & Feed & $\begin{array}{c}F_{1} \\
\text { (Dist) }\end{array}$ & $\begin{array}{c}F_{2} \\
\text { (Dist) }\end{array}$ & $\begin{array}{l}F_{3}, \quad A Q \\
\text { (Bottom) }\end{array}$ & & $\begin{array}{l}F_{3}, \text { ORG } \\
\text { (Bottom) }\end{array}$ & $\begin{array}{c}F_{4} \\
\text { (Bottom) }\end{array}$ \\
\hline Limonene & 8.37 & 0.11506 & $\begin{array}{c}0.1150 \\
6\end{array}$ & $\begin{array}{c}0.014 \\
4\end{array}$ & $\begin{array}{c}0.218 \\
6\end{array}$ & 0 & 0.1806 & 0.1806 & 0.0394 \\
\hline TBHP & 3.73 & 0.10215 & $\begin{array}{c}0.1021 \\
5\end{array}$ & 0 & $\begin{array}{c}0.166 \\
7\end{array}$ & 0.2356 & 0.0328 & 0.0328 & 0 \\
\hline Carvone & $\begin{array}{c}12.2 \\
7\end{array}$ & 0.04034 & $\begin{array}{c}0.0403 \\
4\end{array}$ & 0 & 0 & 0 & 0.129 & 0.129 & 0.141 \\
\hline Carveol & $\begin{array}{c}11.8 \\
9\end{array}$ & 0.00843 & $\begin{array}{c}0.0084 \\
3\end{array}$ & 0 & 0 & 0 & 0.00919 & 0.00919 & 0.01249 \\
\hline $\begin{array}{l}\text { Limonene } \\
\text { 1,2-epoxide }\end{array}$ & $\begin{array}{c}10.1 \\
7\end{array}$ & 0.00241 & $\begin{array}{c}0.0024 \\
1\end{array}$ & 0 & 0 & 0 & 0.0998 & 0.0998 & 0.0797 \\
\hline$t$-butanol & 2.91 & 0.190 & 0.190 & 0.160 & 0.432 & 0.129 & 0.077 & 0.077 & 0.087 \\
\hline Water ${ }^{3}$ & - & - & - & - & - & - & - & - & - \\
\hline Acetone & 2.80 & 0.427 & 0.427 & 0.825 & 0.174 & 0.227 & 0.098 & 0.098 & 0.112 \\
\hline Others ${ }^{4}$ & - & 0.114 & 0.114 & 0.001 & 0.008 & 0.408 & 0.464 & 0.464 & 0.598 \\
\hline $\begin{array}{c}\text { Total mass } \\
\text { (g) }\end{array}$ & - & 7.81 & 7.81 & 1.71 & 1.82 & 0.84 & 1.90 & 1.90 & 1.73 \\
\hline $\mathrm{T}_{\text {reboiler }}(\mathrm{K})$ & - & 318 & 298 & 352 & 373 & 373 & 373 & 300 & 354 \\
\hline$P(\mathrm{kPa})$ & - & 83 & 90.7 & 90.7 & 90.7 & 90.7 & 90.7 & 0.27 & 0.27 \\
\hline$t(\mathrm{~h})$ & - & 6 & 0 & 1.42 & 4.52 & 4.52 & 4.52 & 0 & 0.75 \\
\hline
\end{tabular}

${ }^{1} 800$-Micro-Fractional-Distillation B/R-Instrument system. ${ }^{2}$ Free-water composition of $i$ obtained by GC-MS as Areai/Total-Area, $i$. ${ }^{3}$ Water composition cannot be quantified using a Flame lonization Detector (FID). ${ }^{4}$ Complementary composition includes several compounds, mainly terpenes, products that were not identified with good accuracy by GC-MS. RT: retention time.

\subsection{Computational simulation of the approximate batch distillation model for carvone purification}

The rectifier batch distillation was selected as a technique for separating carvone from the mixture obtained from limonene oxidation; carvone has important applications in the fine chemical industry, where the production capacity is low, but the purity is important.

\section{Continuous distillation simulation}

As a first approximation, a continuous simulation of the carvone separation by continuous distillation was carried out in Aspen Plus ${ }^{\circledR}$ software with the thermodynamic method NRTL-RK, and by using the shortcut DSTWU and the rigorous RadFrac blocks, Table 2. Since the presence of water allows the formation of immiscible $L-L$ phases in equilibrium, which causes a more difficult separation of carvone and the requirement of more rigorous models for the simulation that should consider the LLV equilibria in the column $[17,18]$, the reaction mixture in the feed of this model simulation was established from the results obtained in a flash evaporation of the reaction mixture to remove volatiles and large amounts of water. These preliminary calculations were executed to obtain optimized parameters of the number of ideal stages $N=13$, adjusted distillate flow rate $L_{D}=0.4745 \mathrm{kmol} h^{-1}$ and internal reflux ratio $r$ to be used as approximate design parameters for the batch distillation model. The values of relative volatility a were calculated for the feed composition in Table 2 using the NRTL-RK thermodynamic method; after a sensitive analysis of the bubble and dew points at different thermodynamic models were compared, Figure 5. Since no significant differences were observed for the simulation of the dew points among the selected thermodynamic methods, the Redlich-Kwong equation of state was selected to model the vapor phase. Likewise, the activity coefficient model NRTL was selected to model the liquid phase, as the simulation of the bubble points was similar, except by the ideal model. Although there are intrinsic differences among the selected thermodynamic 


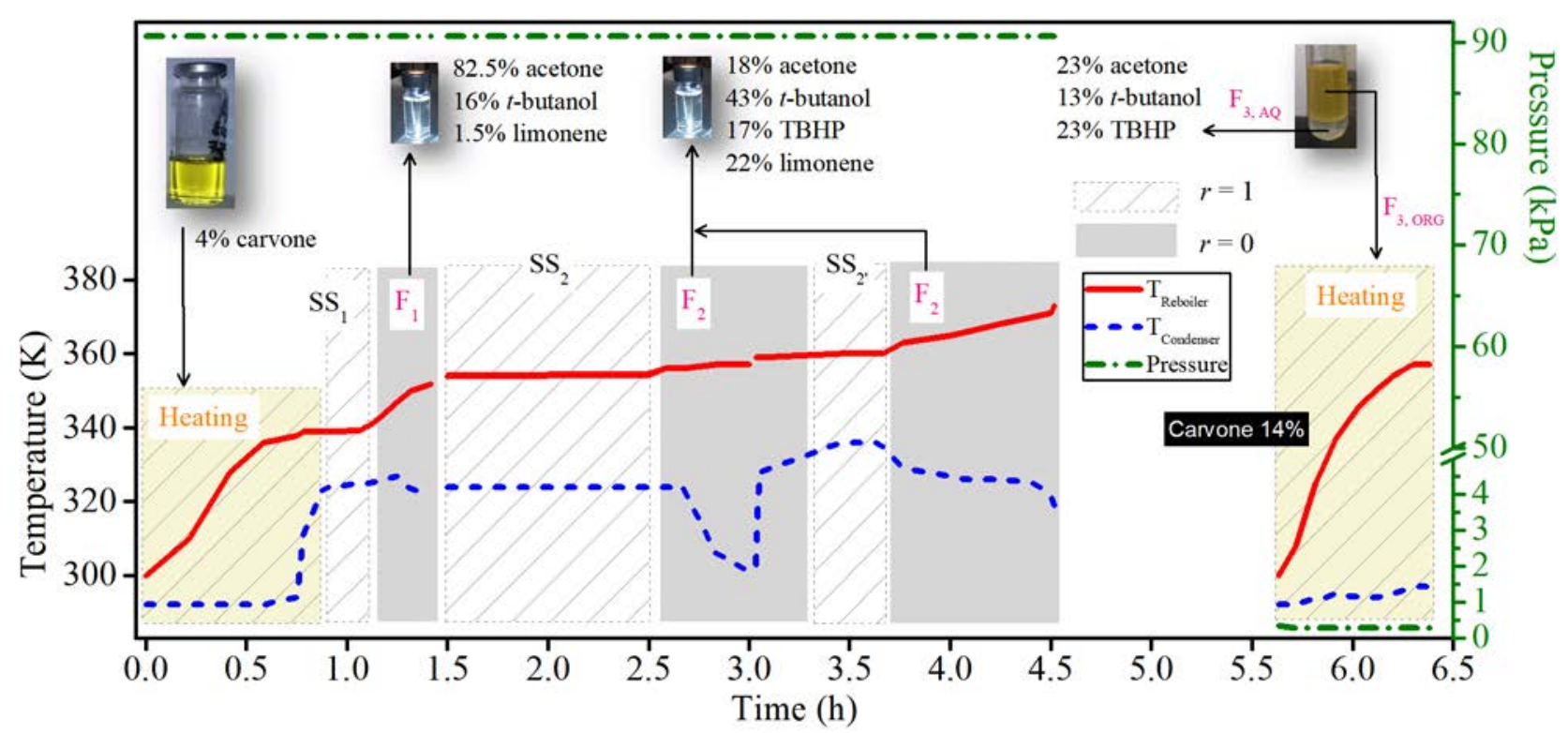

Figure 3 Spinning Band fractional distillation of limonene reaction mixture in a batch mode. Conditions: CTR operation policy, $7.8 \mathrm{~g}$ mixture, $0.27 \mathrm{kPa}, 90.7 \mathrm{kPa}$. SS: steady-state, F: distillate fraction, $r$ : internal reflux ratio

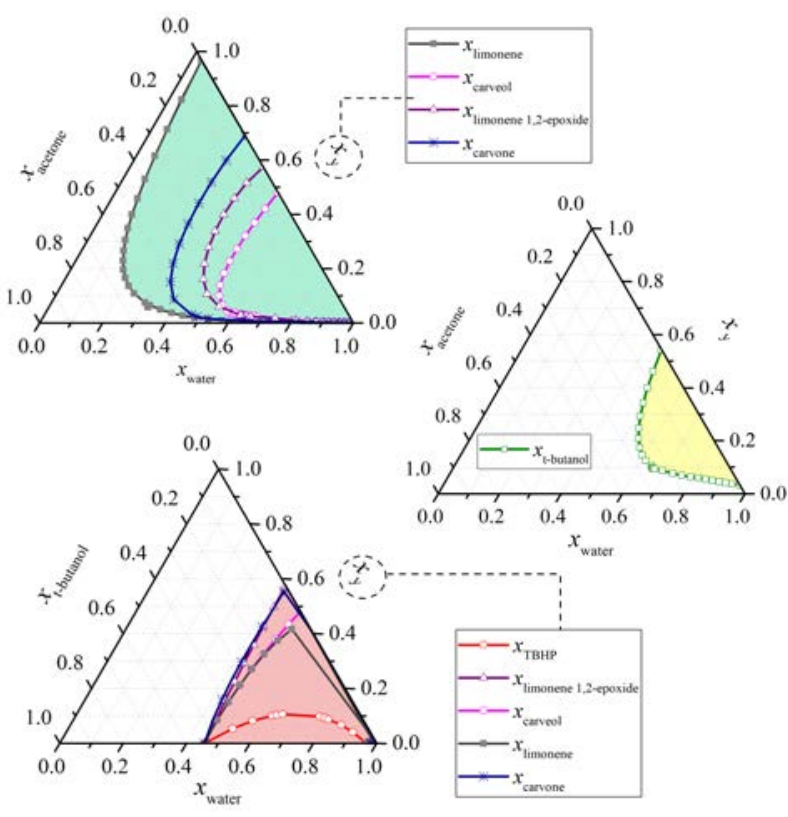

Figure $\mathbf{4}$ Ternary L-L equilibrium of the main components in limonene oxidation. Conditions: Aspen Plus ${ }^{\circledR}$ simulation, NRTL-RK, $90.7 \mathrm{kPa}, 363 \mathrm{~K}$

models [19], there are several studies that properly correlate the physical and thermodynamic properties of mixtures containing terpenes that were simulated by models such as UNIQUAC, WILSON, UNIF-DMD, NRTL, among others [16, 20-23]

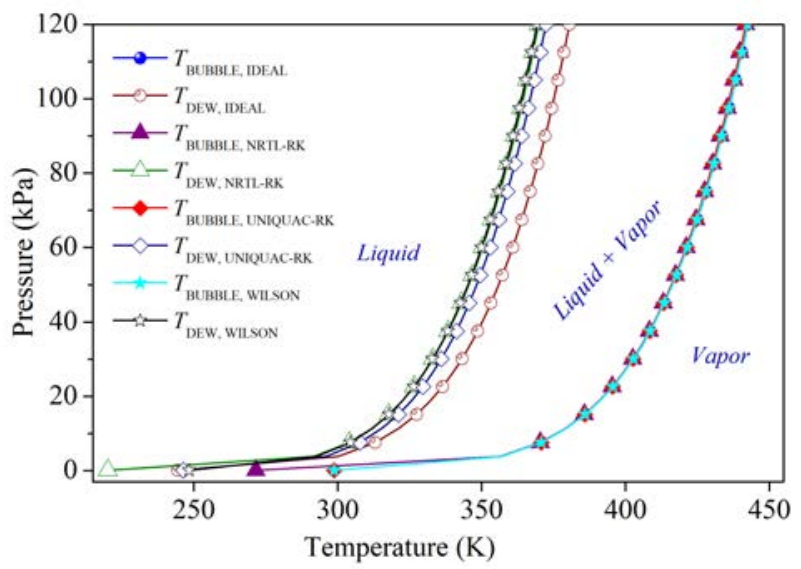

Figure 5 Bubble and dew point curves simulation of the feed distillation mixture. Physical Property Models in Aspen Plus ${ }^{\circledR}$ : IDEAL, NRTL-RK, UNIQUAC-RK, WILSON

\section{Batch distillation simulation}

The fractional batch distillation simulation results using the approximate model and the design parameters obtained by the continuous simulation (13 ideal stages, $r=0.084,7.5 \mathrm{kPa}, L_{D}=0.4547 \mathrm{kmolh}^{-1}$ ) are presented in Figure 6. The molar holdups in the internal stages $H_{j}$ and in the condenser drum $H_{c}$, were defined in terms of the reboiler holdup $H_{N}$. The internal stages to reboiler holdup ratio was specified as $\phi_{j-N}\left(H_{j} / H_{N}\right)=0.21 \%$. Likewise, the condenser drum to reboiler holdup ratio was indicated as $\phi_{c-N}\left(H_{C} / H_{N}\right)=0.67 \%$. 
Table 2 Continuous fractional distillation simulation for carvone separation

\begin{tabular}{cccc}
\hline Composition & Feed & Distillate & Bottom \\
\hline Limonene & 0.09446 & 0.08858 & 0.16680 \\
\hline TBHP & 0.14514 & 0.15693 & $9.44 x 10^{-5}$ \\
\hline Carvone & 0.03691 & $9.97 \times 10^{-7}$ & 0.49113 \\
\hline Carveol & 0.02139 & $1.41 \times 10^{-11}$ & 0.28458 \\
\hline Limonene & 0.00806 & $4.05 x 10^{-3}$ & 0.05740 \\
1,2-epoxide & & & \\
\hline$t$-butanol & 0.04769 & 0.05156 & $6.18 x 10^{-11}$ \\
\hline Water ${ }^{2}$ & 0.61243 & 0.66220 & $5.57 x 10^{-11}$ \\
\hline Acetone & 0.03392 & 0.03668 & $3.76 x 10^{-11}$ \\
\hline Total flow $\left(\mathrm{kmol} h^{-1}\right)$ & 9.562 & 8.8437 & 0.7187 \\
\hline $\mathrm{T}(\mathrm{K})$ & 299 & 295.5 & 298 \\
\hline Density $\left.(\mathrm{kg} \mathrm{m})^{-3}\right)$ & 927.15 & 926.22 & 891.87 \\
\hline$P(\mathrm{kPa})$ & 7.5 & & \\
\hline $\mathrm{N}\left(N_{\text {min }}\right)$ & $13(4.06)$ & & \\
\hline $\mathrm{R}\left(R_{\text {min }}\right)$ & 0.092 & & \\
\hline$r$ & $0.0314)$ & & \\
\hline$N_{\text {feed }}$ & 0.084 & \\
\hline
\end{tabular}

${ }^{1}$ Feed composition established from the results obtained in a flash evaporation of the reaction mixture to remove volatiles. ${ }^{2}$ Water content obtained considering mainly the amount entering the reactor. Conditions: Aspen Plus ${ }^{\circledR}$ simulation considering only the main compounds detected by GC-MS, NRTL-RK, DSTWU, and RadFrac blocks.

The total operation time for the separation is predicted as $5.25 \mathrm{~h}$, excluding the time to achieve the steady-state in the startup that was set as $0.25 \mathrm{~h}$. Three distillate cuts were proposed to achieve a higher carvone purification as a distillate product, since carvone concentration in the reboiler $x_{13, \text { carvone }}$ was predicted to increase only from $4 \%$ at the feed to around $50 \%$ after $5.0 \mathrm{~h}$ or operation, Figure 6a. Additionally, a constant internal reflux ratio per cut policy was established for the simulation instead of the CTR operation policy, since the last one usually requires more energy due to the intermittent steady-state equilibrium zones in which there are not products withdrawn. The liquid molar fraction in the accumulator of the first distillate cut (Cut1) is mainly composed of $71 \%$ acetone, $27 \% t$-butanol and $2 \%$ water after $0.17 \mathrm{~h}$. The second distillate cut (Cut2) required $4.91 \mathrm{~h}$ after the first cut was collected. The simulation of its composition resulted in a mixture containing $67 \%$ water, $16 \%$ TBHP, $10 \%$ limonene, $4 \% t$-butanol, $1 \%$ acetone and $1 \%$ limonene 1,2-epoxide. The operating time of the final cut (Cut3) was $0.17 \mathrm{~h}$ after the collection of Cut2. Here a sensitive analysis of the internal reflux ratio $r$ was performed to improve carvone separation. A larger internal reflux ratio $r=0.5$ increases the contact time of the phases and the carvone molar fraction in the third accumulator was predicted as $86.5 \%$, with $11 \%$ TBHP and $2 \%$ limonene,
Figure $6 \mathrm{~b}$. In this case, the molar fraction of carvone in the reboiler decreased from 38\% to zerofigure (Figure 6) because it was concentred in the condenser (Figure 6c).

In summary, the simulation of carvone separation by batch distillation can be carried out in four stages. Using total internal reflux ratio $(r=1)$ at start-up, small constant internal reflux $(r=0.084)$ to collect the first (Cut1) and second (Cut2) distillate fractions and the final stage at larger constant internal reflux ratio $(r=0.5)$ to recover the carvone as a distillate product with a purity of $86.5 \%$ (Cut3), Figure 7. Although ideal equipment was assumed in the conceptual design of the distillator, the results on the correction of the ideal stages using some correlations for the estimation are outside the range of application. The distillation occurs at vacuum pressure, the average relative volatility between the light and heavy key components is 50 (relatively large); and the viscosities of the initial mixture is $0.472 \mathrm{cP}$ at the bubble point. The most commonly used empirical correlations for estimating stage efficiency include the Drickamer and Bradford equation as a function of the viscosity of the mixture [24]; the tray efficiency estimated from this correlation was $E_{D N}=35 \%$. However, the expression is limited to a range of efficiencies from $41 \%$ to $88 \%$ (with a deviation of 5 to $13 \%$ ), which covers temperatures from 


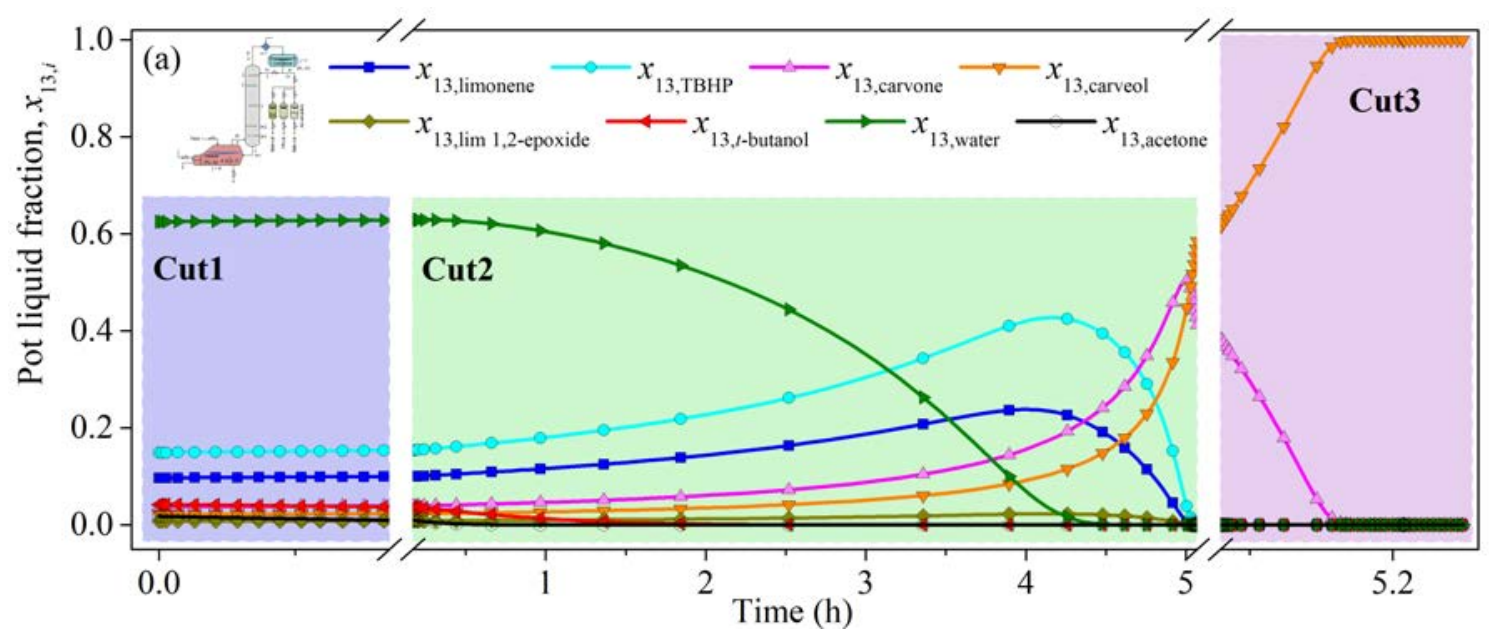

(a)

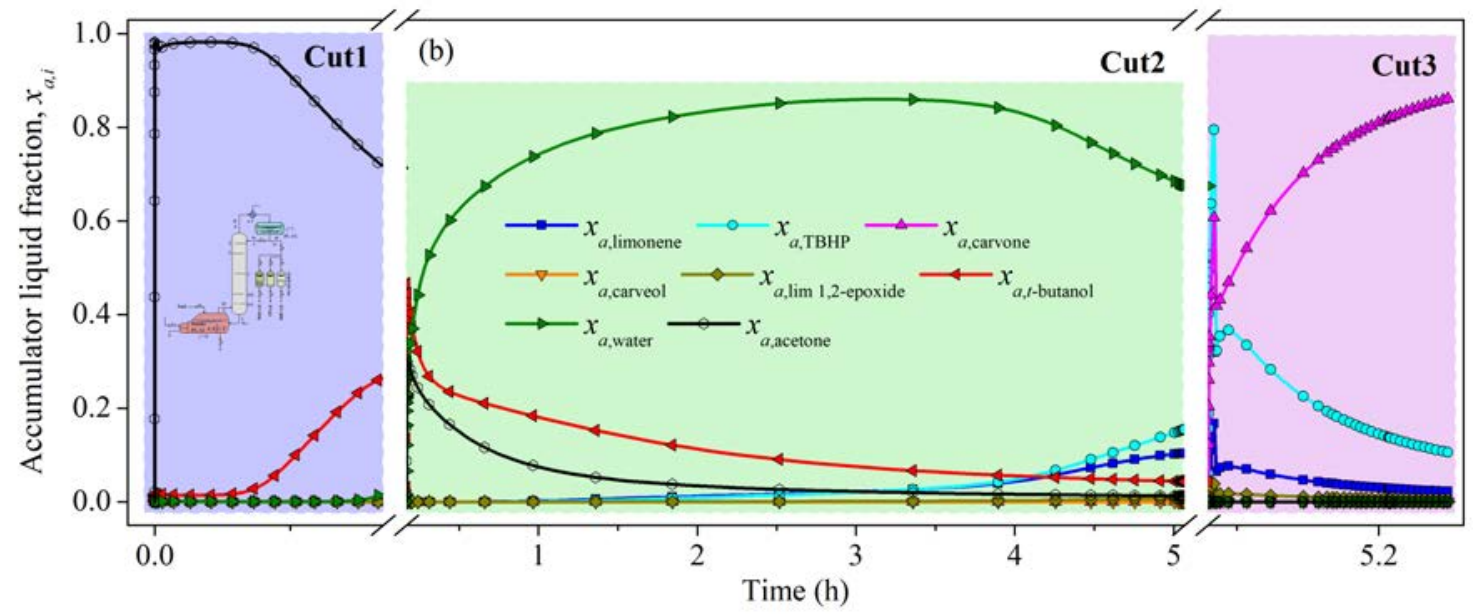

(b)

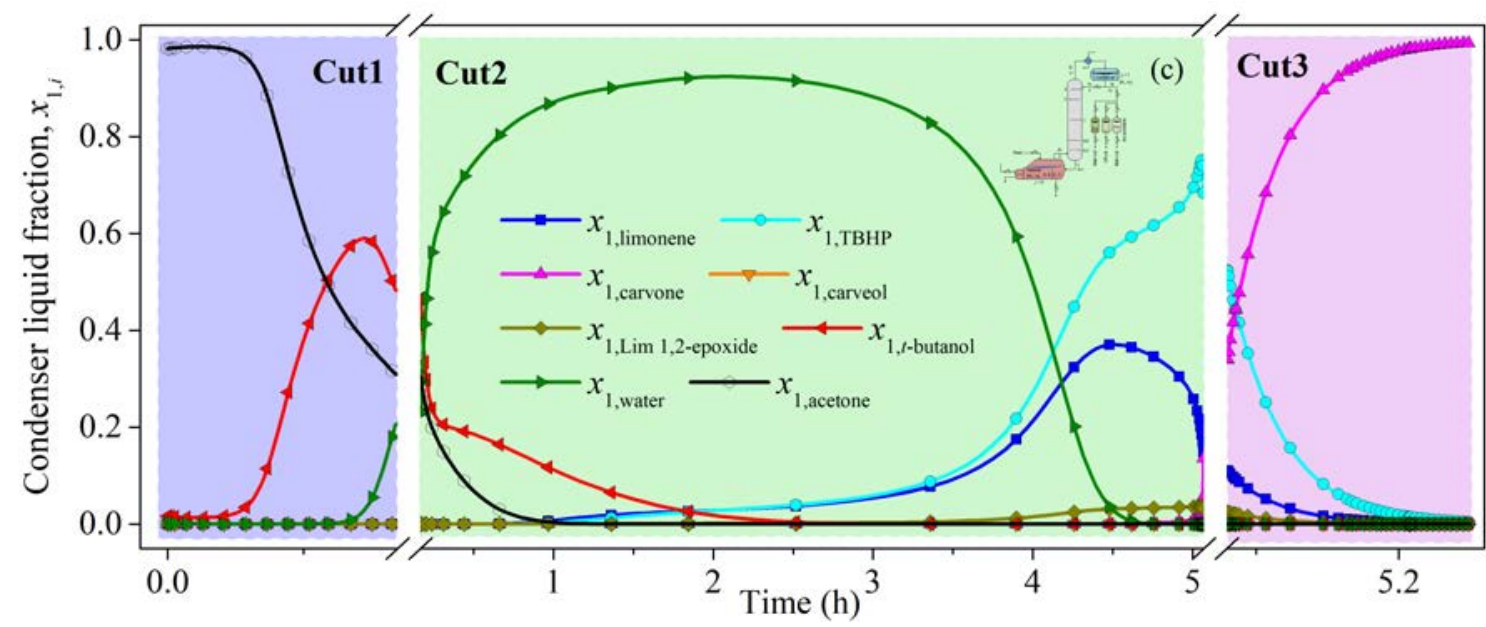

(c)

Figure 6 Simulation of liquid molar composition in the reboiler (a), accumulator (b), and condenser (c) in the batch fractional distillation of carvone. Conditions: constant internal reflux, $L_{D}=0.4745 \mathrm{kmolh}^{-1}, 7.5 \mathrm{kPa}, \phi_{j-N}=0.21 \%, \phi_{c-N}=$ $0.67 \%$, Cut1 $(0.17 \mathrm{~h}, r=0.084)$, Cut2 $(4.91 \mathrm{~h}, r=0.084)$, Cut3(0.17h, $r=0.5)$. Matlab ${ }^{\circ}$ simulation by ode $15 \mathrm{~s}$ 
342 to $488 \mathrm{~K}$, positive pressures (100 to $2500 \mathrm{kPa}$ ), and liquid viscosities between 0.066 to $0.355 \mathrm{cP}$. The $\mathrm{O}^{\prime}$ Connell formulation [24], which is a function of the viscosity and the relative volatility, predicted a slightly lower value of the tray efficiency, $E_{O C}=25 \%$. Although this expression covers a wider range of relative volatilities, the data used only covers a relative volatility from 1.16 to 20.5 . Although, in both cases, the tray efficiencies are small, i.e., real distillation equipment must have a higher number of stages to achieve the separation of carvone with higher purity, it is recommended to estimate the tray efficiency fitting experimental data because the correlations are not adequate for the process conditions.

\section{Nomenclature}

$\begin{array}{ll}E & \text { Stage efficiency } \\ H & \text { Molar holdup (kmol) } \\ K & \text { Distribution coefficient (-) } \\ L & \text { Molar liquid flow rate }\left(\mathrm{kmolh}^{-1}\right) \\ N & \text { Stage N or number of ideal stages (-) } \\ n_{c} & \text { Number of components (-) } \\ r & \text { Internal reflux ratio (-) } \\ T & \text { Temperature (K) } \\ t & \text { Time (h) } \\ P & \text { Pressure (kPa) } \\ R & \text { External reflux ratio (-) } \\ x & \text { Molar liquid fraction (-) } \\ y & \text { Molar vapor fraction (-) }\end{array}$

Greek letters

$$
\begin{array}{ll}
\alpha & \text { Relative volatility (-) } \\
\phi & \text { Holdup ratio (-) }
\end{array}
$$

Sub- and Superscripts

$\begin{array}{ll}a & \text { Distillate accumulator } \\ c & \text { Condenser-drum } \\ D & \text { Distillate } \\ i & \text { Component } \\ j & \text { Internal stages }\end{array}$

\section{Abbrevations}

$\begin{array}{ll}\text { DB } & \text { Drickamer and Bradford } \\ \text { DSTWU } & \text { DiSTillation-Winn-Underwood Block } \\ \text { FID } & \text { Flame lonization Detector } \\ \text { GC-MS } & \text { Gas Chromatography-Mass Spectroscopy } \\ \text { OC } & \text { O'Connell } \\ \text { NRTL } & \text { Non-Random Two-Liquid } \\ \text { RK } & \text { Redlich-Kwong } \\ \text { TCD } & \text { Thermal Conductivity Detector } \\ \text { UNIQUAC } & \text { Universal Quasichemical }\end{array}$

\section{Conclusions}

Carvone, a naturally occurring compound with relevant applications in the specialty chemical industry, was synthesized from limonene over the heterogeneous catalyst $\mathrm{FePCCl}_{16}-\mathrm{NH}_{2}-\mathrm{SiO}_{2}$ and using TBHP as an oxidant in a batch reactor. The further fractionation of the reaction mixture by distillation leads to the increase in carvone concentration. Non-ideality of liquid phase has to be corrected by adequate selection of thermodynamic models for the activity coefficients such as NRTL, UNIQUAC, UNIFAC or WILSON and compared with experimental data to validate the most adequate model. Redlich Kwong vapor phase seems to behave similarly as predicted with the ideal thermodynamic model. Since terpenes usually have high normal boiling points, it is preferable to fractionate them under vacuum conditions. After a large number of volatile compounds lacetone, $t$-butanol, and water) are removed from the reaction mixture, carvone purity by fractional distillation is predicted as $86.5 \%$ in a third distillate cut, according to the approximate model used. Both experimental and simulation results showed that fractional distillation is a suitable technique for concentrating carvone. However, the presence of water allows the formation of immiscible $L-L$ phases in equilibrium, which causes a more difficult separation of carvone and the requirement of more rigorous models for the simulation that should consider the LLV equilibria in the column. Additional experimental data obtained using the constant reflux policy are required to compare and validate the approximate model of the batch distillation, since the data obtained by the CTR policy requires further parameters for a simulation and it is not an attractive operational mode from the economical point of view. Thus, a more efficient carvone separation could be reached by optimization of the operating conditions in the distillation column.

\section{Declaration of competing interest}

We declare that we have no significant competing interests including financial or non-financial, professional, or personal interests interfering with the full and objective presentation of the work described in this manuscript.

\section{Acknowledgments}

The authors thank funding from Universidad de Antioquia and from the Ministry of Science, Technology and Innovation, the Ministry of Education, the Ministry of Industry, Commerce and Tourism, and ICETEX, Programme Ecosistema Científico-Colombia Científica, from the Francisco José de Caldas Fund, Grant RC-FP44842-212-2018. To proffessor Dr. Elena Stashenko and the Eng. Andrés Ramirez at the Centro Nacional de Investigaciones para la Agroindustrialización de Especies Vegetales Aromáticas y Medicinales Tropicales (CENIVAM) at Universidad Industrial de Santander, for their support 


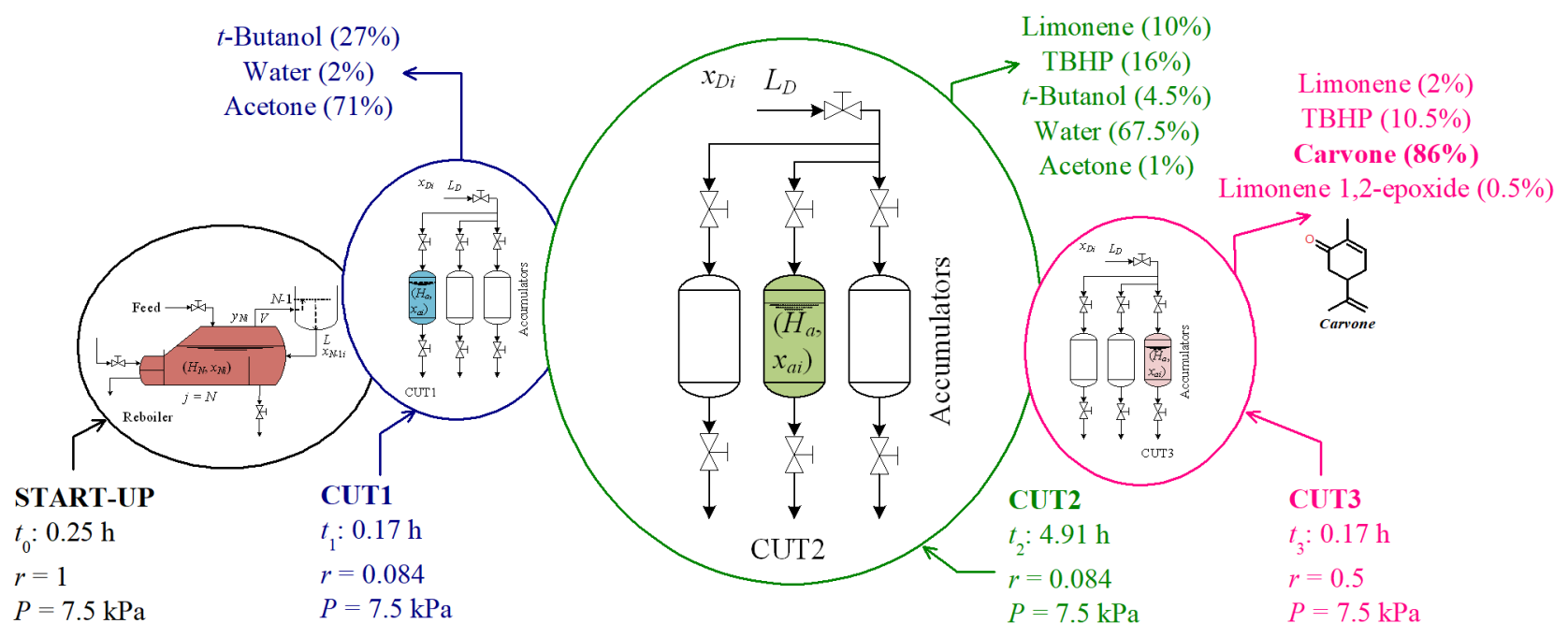

Figure 7 Summary of the approximate model simulation of the batch fractional distillation of carvone. Conditions: constant internal reflux, $L_{D}=0.4745 \mathrm{kmol} \mathrm{h}^{-1}, 7.5 \mathrm{kPa}, \phi_{j-N}=0.21 \%, \phi_{c-N}=0.67 \%$. Matlab® simulation by ode $15 \mathrm{~s}$

in the batch distillation experiments.

J.A. thanks COLCIENCIAS for the doctoral scholarship (call 694 of 2014).

\section{Funding}

This work was supported by Universidad de Antioquia and from the Ministry of Science, Technology and Innovation, the Ministry of Education, the Ministry of Industry, Commerce and Tourism, and ICETEX, Programme Ecosistema Científico-Colombia Científica, from the Francisco José de Caldas Fund, Grant RC-FP44842-212-2018.

\section{Author contributions}

$J A B$ and $A L V$ wrote the manuscript, chose references and contributed to the discussions. JAB edited the figures and references. All authors read and approved the final manuscript version to be submitted.

\section{Data availability Statement}

Chemical reactions and quantification were carried out at Grupo Catálisis Ambiental at Universidad de Antioquia, Medellín-Colombia. Gas chromatograph (GC) Agilent 7890A equipped with FID, TCD and mass spectrometer (MS) Agilent $5975 \mathrm{C}$ detectors was used for the quantification. Distillation fractions were obtained in an 800-Micro-Fractional-Distillation system from B/R-Instruments Corp., in the Centro Nacional de Investigaciones para la Agroindustrialización de Especies Vegetales Aromáticas y Medicinales Tropicales
(CENIVAM) at Universidad Industrial de Santander, Bucaramanga-Colombia.

\section{References}

[1] Y. Xiong and et al., "Removal of three kinds of phthalates from sweet orange oil by molecular distillation," LWT - Food Science and Technology, vol. 53, no. 2, Oct. 2013. [Online]. Available: https://doi.org/10.1016/j.lwt.2013.04.012

[2] J. A. Becerra and A. L. Villa, "Clean limonene transformations into added-value compounds of fine chemistry using heterogeneous catalysis," in Advances in Chemistry Research Volume 47, J. C. Taylor, Ed. Hauppauge, NY: Nova science publishers, 2019.

[3] C. Navarrete, J. Gil, D. Durango, and C. Garcia, "Extracción y caracterización del aceite esencial de manadarina obtenido de residuos agroindustriales," DYNA, vol. 77, no. 162, 2010. [Online]. Available: https://revistas.unal.edu.co/index.php/dyna/ article/view/15779

[4] D. Pergentino, F. Ferreira, and R. Nóbrega, "Influence of the chirality of (r)-(-)- and (s)-(+)-carvone in the central nervous system: a comparative study," Chirality, vol. 19, no. 4, May. 5, 2007. [Online]. Available: https://doi.org/10.1002/chir.20379

[5] P. M. Rhodes and N. Winskill, "Microbiological process for the preparation of 1-carvone," U.S. Patent 4,495,284, Jan. 22., 1985. [Online]. Available: https://patents.google.com/patent/ US4495284A/en

[6] P. N. Davey, C. P. Newman, W. A. Thiam, and C. L. Tse, "Preparation of carvone," Patent WO 0058 253, Oct. 5., 2000. [Online]. Available: https://patents.google.com/patent/W02000058253A1/en

[7] J. A. Becerra, L. M. González, and A. L. Villa, "A bio-inspired heterogeneous catalyst for the transformation of limonene from orange peel waste biomass into value-added products," Catalysis Today, vol. 302, Mar. 15, 2018. [Online]. Available: https://doi.org/10. 1016/j.cattod.2017.07.012

[8] I. M. Mujtaba. (2004) Batch distillation: Design and operation. Imperial College Press. [Online]. Available: https://tinyurl.com/ yfpmotfq

[9] P. C. Wankat. (2012) Separation process engineering: Includes mass transfer analysis, third edition. Prentice Hall. [Online]. Available: http://repository.um-palembang.ac.id/id/eprint/9143/1/ separation-process-engineeringbook $\% 20 \% 28 \% 20$ PDFDrive.com $\%$ $20 \% 29$.pdf 
[10] E. L. Foletto and et al., "Operation parameters of a small scale batch distillation column for hydrous ethanol fuel (hef) production," Ingeniería e Investigación, vol. 35, no. 1, Jan. 2015. [Online]. Available: http://dx.doi.org/10.15446/ing.investig.v35n1.46969

[11] T. Fang, M. Goto, M. Sasaki, and T. Hirose, "Combination of supercritical $\mathrm{CO}_{2}$ and vacuum distillation for the fractionation of bergamot oil," Journal of Agricultural and Food Chemistry, vol. 52, no. 16, Jul. 7, 2004. [Online]. Available: https://pubs.acs.org/doi/ abs/10.1021/jf049895f

[12] R. N. Almeida, R. d. P. Soares, and E. Cassel, "Fractionation process of essential oils by batch distillation," Brazilian Journal of Chemical Engineering, vol. 35, no. 3, 2018. [Online]. Available: https://doi.org/10.1590/0104-6632.20180353s20170216

[13] S. C. Beneti and et al., "Fractionation of citronella (cymbopogon winterianus) essential oil and concentrated orange oil phase by batch vacuum distillation," Journal of Food Engineering, vol. 102, no. 4, Feb. 2011. [Online]. Available: https://doi.org/10.1016/j. jfoodeng.2010.09.011

[14] R. Barrera, A. L. Villa, and C. Montes, "Modeling and simulation of a batch distillation column for recovering limonene epoxide," Revista EIA, vol. 9, no. 18, 2012. [Online]. Available: https: //revistas.eia.edu.co/index.php/reveia/article/view/265

[15] I. D. Wilson, E. R. Adlard, M. Cooke, and C. F. Poole. (2000) Encyclopedia of separation science. Elsevier Science Ltd. [Online]. Available: https://books.google.com.co/books?id=hMBTAAAAMAAJ

[16] X. Li and K. Tamura, "(ternary liquid + liquid) equilibria for (water + acetone + a-pinene, or B-pinene, or limonenel mixtures," The Journal of Chemical Thermodynamics, vol. 42, no. 11, Nov. 2010. [Online]. Available: https://doi.org/10.1016/j.jct.2010.06.004

[17] C. A. Sánchez, G. Rodríguez, and M. A. Gómez, “Herramientas geométricas para el diseño básico de columnas de destilación con mezclas azeotrópicas heterogéneas ternarias. i. cáculo del reflujo mínimo," Revista EIA, vol. 9, no. 18, Sep. 27, 2013. [Online]. Available: https://revistapostgrado.eia.edu.co/index.php/ reveia/article/view/266

[18] C. A. Sánchez, L. Estupiñán, and M. A. Salazar, “Herramientas para la caracterización termodinámica de sistemas ternarios en destilación," Revista EIA, no. 13, Nov. 25, 2013. [Online]. Available: https://repository.eia.edu.co/handle/11190/184

[19] A. Farajnezhad and et al., "Correlation of interaction parameters in wilson, nrtl and uniquac models using theoretical methods," Fluid Phase Equilibria, vol. 417, Jun. 15, 2016. [Online]. Available: https://doi.org/10.1016/j.fluid.2016.02.041

[20] D. Gonçalves and et al., "Fractionation of orange essential oil using liquid-liquid extraction: Equilibrium data for model and real systems at 298.2 k," Fluid Phase Equilibria, vol. 399, Aug. 15, 2015. [Online]. Available: https://doi.org/10.1016/j.fluid.2015.04.022

[21] C. M. Oliveira and et al., "Liquid-liquid equilibrium data for the system limonene + carvone + ethanol + water at $298.2 \mathrm{k}$," Fluid Phase Equilibria, vol. 360, Dec. 25, 2013. [Online]. Available: https://doi.org/10.1016/j.fluid.2013.09.057

[22] L. Sun and et al., "Measurement and correlation of (vapor + liquid) equilibrium data for a-pinene + p-cymene + (S)-(-)-limonene ternary system at atmospheric pressure," The Journal of Chemical Thermodynamics, vol. 58, Mar. 2013. [Online]. Available: https: //doi.org/10.1016/j.jct.2012.10.017

[23] I. Batiu, "Vapor-liquid equilibria in the binary system (-)-beta-pinene $+(+)$-fenchone: Analysis in terms of group contributions models of some binary systems containing terpenoids," Fluid Phase Equilibria, vol. 227, no. 1, Jan. 1, 2005. [Online]. Available: https://doi.org/10.1016/j.fluid.2004.10.032

[24] J. D. Seader, E. J. Henley, and D. K. Roper. (2011) Separation process principles, chemical and biochemical operations, third edition. John Wiley \& Sons, Inc. [Online]. Available: https://www.academia.edu/37158509/ _CBE3233_Separation_Process_Principles_3e?from=cover_page 